\title{
Consumption of Farm Output and Economic Growth in the Old Northwest, 1800-1860
}

\section{Eleanor von ENDE AND Thomas Weiss}

In this article we present the first estimates of output per capita for the Old Northwest in the years before 1840 . The results indicate that the region grew quite rapidly, even during its earliest formative years. Its performance relative to the nation depends on the definition of output.

$\mathbf{T}$ he Old Northwest was, until the 1980s, the quintessential story of American economic success. It may have been "the most significant single region from the standpoint of understanding the nature of economic growth in the United States during the nineteenth century. "1 Its history, however, has not received the attention it seems to deserve, especially not in comparison to the profusion of studies about the Southern plantation-slave economy. Although the region's emergence as an industrial power has been investigated some, the story of its earlier success-the transition from frontier to breadbasket-has not been well documented. ${ }^{2}$

This neglect has resulted in part from a lack of statistics. We try to correct this deficiency by presenting the first estimates of per capita output for the region. Our conjectures indicate that the Old Northwest was not as advanced as the nation in the early nineteenth century, but that it grew more rapidly. The region's per capita output was below the nation's throughout the period 1800 to 1860 , but it increased by at least 1.4 percent per year over the entire period, and by more than 2 percent per year between 1840 and 1860 . Our figures, moreover, may understate the region's performance; we obtain higher rates of growth when we incorporate a positive income elasticity of demand for agricultural products into the conjectural estimating equation.

The Journal of Economic History, Vol. 53, No. 2 (June 1993). (C) The Economic History Association. All rights reserved. ISSN 0022-0507.

Eleanor von Ende is Assistant Professor of Economics, Texas Tech University. Thomas Weiss is Professor of Economics, University of Kansas, and Research Associate of the National Bureau of Economic Research. We thank Lou Cain and George Grantham for comments on an earlier draft.

'Easterlin, "Farm Production," p. x. The region is made up of Illinois, Indiana, Ohio, Michigan, and Wisconsin, and is also referred to as the East North Central.

${ }^{2}$ Recent exceptions are Meyer, "Midwestern Industrialization," and Atack and Bateman, To Their Own Soil. 


\section{METHOD OF ESTIMATION}

Gross domestic product can be estimated as the unduplicated sum of the output originating in three sectors: agriculture, nonagriculture (excluding shelter), and shelter. ${ }^{3}$

$$
\left(G D P_{N}\right)=A_{c}+A_{x}+W_{n} L F_{n}+O_{s}
$$

The output of agriculture consists predominantly of the marketed value of crop and livestock production, which is made up of output that was consumed within the region of production $\left(A_{c}\right)$ and that which was exported $\left(A_{x}\right)$ from the region. Nonagricultural output is the product of the number of workers in the industry, $L F_{n}$, and their average output, $W_{n}$. The last term $\left(O_{s}\right)$ is the rental value of dwellings. ${ }^{4}\left(G D P_{n}\right)$ constitutes our narrow measure of output.

A broader measure of output $\left(G D P_{B}\right)$ can be obtained by adding the value of two unconventional items $\left(A_{u}\right)$ : home manufacturing produced on farms, as well as off, and farm improvements.

$$
\left(G D P_{B}\right)=A_{c}+A_{x}+A_{u}+W_{n} L F_{n}+O_{s}
$$

We first estimated the components of the Old Northwest's output in the base year of 1840 , then extrapolated them backward to 1800 . The 1840 figures were obtained by allocating to the region a share of the unduplicated national output of each industry. ${ }^{5}$ The national figures for GDP and most industries were taken from Robert Gallman's work. ${ }^{6}$ Because we treat services as a separate industry, we adjusted his figures to remove the value of intermediate services consumed in the production of the other sectors' outputs. ${ }^{7}$ We thus obtained an unduplicated value of output for each industry, the sum of which equals gross domestic product.

In order to estimate agricultural output for 1800 through 1830 , we first identified the key exports from the region and deducted their 1840 value from the marketed value of agricultural output for that year. The

\footnotetext{
${ }^{3}$ This equation is a revised version of that employed by David in "The Growth of Real Product." Ours, however, is expressed in terms of total product, not product per capita; we treat shelter as a separate component; and we estimate nonagricultural output independently of output per worker in agriculture, at least for the period 1820 to 1840 . For details see Weiss, "Economic Growth Before 1860," and Weiss, "Estimates."

${ }^{4}$ The rental value of dwellings $\left(O_{s}\right)$ cannot be easily assigned to either the agricultural or nonagricultural sector, at least not in the sense that we know which labor force produced it.

${ }^{5}$ We modified the procedures laid out by Easterlin and Cohn and took advantage of better data on the output of the service industries, productivity growth in manufacturing, and the labor force, that have become available since Easterlin produced his estimates. Easterlin, "Regional Income Trends," p. 545; Easterlin, "Farm Production," pp. 100-109; and Cohn, "Antebellum Regional Incomes," pp. 331-36. Also see von Ende, "Conjectural Estimates," especially chap. 4.

${ }^{6}$ Gallman, "Gross National Product;" and Gallman and Weiss, "The Service Industries."

${ }^{7}$ Except for shelter, government, and personal services, the value of intermediate services consumed in each industry was assumed to be proportional to the industry's share of GDP. There were no intermediate services consumed in the three exceptions.
} 
residual is the agricultural output consumed within the region, which we shall call basic agricultural output (BAO). For our initial estimates we have assumed that this figure remained constant on a per capita basis going back to 1800 , an assumption that accords with the estimation methods underlying Marvin Towne and Wayne Rasmussen's national figures. ${ }^{8}$ Whereas Towne and Rasmussen specified constant per capita consumption for individual products, we are assuming constancy in the per capita value of all those products combined. ${ }^{9}$ Multiplying by the population in each of the earlier years, we obtained the aggregate amount produced in the region. To these figures we added estimates of the value of products that were shipped interregionally. The sum is the region's agricultural output, narrowly defined.

The products for which we estimated exports from the Old Northwest are corn, wheat, flour, and pork. ${ }^{10}$ The narrative histories of the region, as well as William Hutchinson's estimates of potential surpluses for 1870 , indicate that these were the only substantial exports from the region. ${ }^{11}$ According to Hutchinson's evidence these items accounted for nearly 95 percent of the region's likely exports.

Output in the nonagricultural sector is the product of the workers engaged therein and their average output per worker. ${ }^{12}$ Nonagricultural output per worker $\left(W_{n}\right)$ was estimated for each benchmark year 1800 through 1830 by extrapolating the 1840 figure backward on an index constructed from the available pieces of evidence. For the period 1820 to 1840 it was possible to estimate the growth of manufacturing output per worker directly from evidence for those industries, but of necessity, in the years before 1820 we had to assume that it moved in parallel with that of agricultural output per worker. ${ }^{13}$ The latter assumption was used to gauge the growth of output per worker in the nonmanufacturing industries as well. The manufacturing and nonmanufacturing figures were combined in proportion to their 1840 shares of the labor force to obtain the index used for extrapolation.

\footnotetext{
8 The assumption of constant per capita consumption may not be the ideal basis on which to estimate agricultural output, but it is not entirely unrealistic, and it is practical. See Gallman, "The Statistical Approach," pp. 71-77 and the discussion below where we show that changes in the composition of the region's population had little effect on consumption.

9 Towne and Rasmussen, "Farm Gross Product," estimated the output of some agricultural products in more direct fashion, but the combined output of those products amounted to only 6 percent of farm gross product in 1840. The output of corn, wheat, and tobacco, included an estimate of exports.

${ }^{10}$ See von Ende, "Conjectural Estimates," chap. 6, for details.

"Hutchinson, "U.S. Regional Growth," table A.4.

12 The nonagricultural industries are manufacturing, mining, construction, and services other than shelter.

${ }^{13}$ The evidence on manufacturing productivity growth comes from Sokoloff, "Productivity Growth," p. 698, table 13.6. His figure of 2.3 percent per year productivity growth may be more indicative of progress in the Northeast, but we used it to be consistent with the conjectures for the nation. See Weiss, "Economic Growth Before 1860." The results for the Old Northwest, especially for periods of 20 years or more, are not sensitive to this assumption.
} 
Finally, we added estimates of the rental value of dwellings, the value of home manufacturing, and the value of farm improvements. For 1840 through 1860 the figures come from Gallman's estimates of national product. ${ }^{14}$ For earlier years, the value of shelter was calculated as 20 percent of the stock of residential dwellings; the value of farm improvements was derived as the product of the number of acres cleared in each year times the value of improvements per acre; and the value of home manufacturing was estimated as the product of population and the 1840 to 1860 average value of home manufacturing per capita. ${ }^{15}$ The first of these three items completes the estimate of the narrowly defined measure $\left(G D P_{N}\right)$, the addition of the latter two yields the broader measure of output $\left(G D P_{B}\right)$.

\section{RESULTS}

Over the period 1800 to 1860 , the region performed admirably, especially in terms of the narrow measure of gross domestic product. Output per capita in the Old Northwest grew by 1.44 percent per year, nearly 0.4 percent faster than the rate of growth achieved by the nation (see Table 1). During the statistical dark age as well, from 1800 to 1840 , the region outpaced the nation according to the narrow measure of output per capita, 1.11 percent per year compared to only 0.8 percent. As a consequence, although the region's per capita output was only 71 percent of the nation's at the beginning of the century, it had risen to 79 percent by 1840 .

When the output measure is broadened to include items of importance to a developing farm region, the Old Northwest's level and rate of growth of output per capita appear much closer to those of the nation. The region's output per capita began the century just above 90 percent of the nation's. In the subsequent 40 years it grew somewhat more slowly than the nation's, 0.53 versus 0.66 percent per year, and its relative position deteriorated slowly, falling to 84 percent in 1830 and 86 percent in 1840. Its relative position improved after 1840 .

The two measures describe noticeably different pictures of the region's performance, and this should be kept in mind in the ensuing discussion. Limited space requires that we focus on the narrow measure, primarily because it can be compared more readily to figures used in previous studies. Moreover, the estimates of the less conventional items, farm improvements and home manufacturing, that broaden the

\footnotetext{
${ }^{14}$ Gallman, "Gross National Product," p. 35; and Gallman and Weiss, "The Service Industries," p. 288, table 1.

${ }^{15}$ See Gallman, "Gross National Product," pp. 71-76, and von Ende and Weiss, "Appendix," for details. The 20 percent figure for shelter was derived from the data for 1840 to 1860 . Gallman provided us with his dwelling stock estimates for $1800,1805,1815$, and 1840 . We obtained values for other years by interpolation.
} 
TABLE 1

OUTPUT PER CAPITA IN THE OLD NORTHWEST AND THE UNITED STATES, $1800-1860$

\begin{tabular}{lcccccccc}
\hline & \multicolumn{2}{c}{ Narrow Definition of Output } & & \multicolumn{2}{c}{ Broad Definition of Output } \\
\cline { 2 - 3 } & $\begin{array}{c}\text { Old } \\
\text { Northwest (\$) }\end{array}$ & $\begin{array}{c}\text { United } \\
\text { States (\$) }\end{array}$ & Ratio & & $\begin{array}{c}\text { Old } \\
\text { Northwest (\$) }\end{array}$ & $\begin{array}{c}\text { United } \\
\text { States (\$) }\end{array}$ & Ratio \\
\hline 1800 & 47 & 66 & 0.71 & & 70 & 77 & 0.91 \\
1810 & 50 & 69 & 0.72 & & 72 & 82 & 0.88 \\
1820 & 58 & 72 & 0.81 & & 75 & 84 & 0.89 \\
1830 & 61 & 79 & 0.77 & & 76 & 90 & 0.84 \\
1840 & 73 & 91 & 0.80 & & 87 & 101 & 0.86 \\
1850 & 83 & 100 & 0.83 & & 98 & 111 & 0.88 \\
1860 & 111 & 124 & 0.90 & & 124 & 134 & 0.93
\end{tabular}

Average Annualized Rates of Change

$\begin{array}{lllll}1800-1810 & 0.59 & 0.48 & 0.24 & 0.52 \\ 1810-1820 & 1.45 & 0.34 & 0.39 & 0.27 \\ 1820-1830 & 0.60 & 0.96 & 0.13 & 0.72 \\ 1830-1840 & 1.82 & 1.41 & 1.35 & 1.15 \\ 1800-1820 & 1.02 & 0.41 & 0.31 & 0.39 \\ 1820-1840 & 1.21 & 1.19 & 0.74 & 0.93 \\ 1840-1860 & 2.10 & 1.57 & 1.80 & 1.42 \\ 1800-1840 & 1.11 & 0.80 & 0.53 & 0.66 \\ 1800-1860 & 1.44 & 1.06 & 0.95 & 0.92\end{array}$

Notes: The region's estimates are based on the assumption that basic agricultural consumption per capita remained constant from 1800 to 1840 at a value of $\$ 31$. The national figures are based on the Towne and Rasmussen estimates of farm gross product, which implicitly assumed that per capita consumption of most farm products remained constant over those years. For the sake of completeness we estimated output per capita for the region in 1850 , but did so in indirect fashion by apportioning the region's growth from 1840 to 1860 between the two decades in the same proportions as occurred for the nation.

Sources: Towne and Rasmussen, "Farm Gross Product"; von Ende, "Conjectural Estimates"; von Ende and Weiss, "Appendix"; and Weiss, "Economic Growth Before 1860," table 1.6.

measure are not as secure as those of the marketed items that make up the narrow measure.

The region's growth, measured by the narrower version, appears not to have been very steady on a decade to decade basis. This should not be too surprising for a frontier region that was experiencing very rapid influxes of population and labor. The fluctuations evident in the data, especially the rapid growth between 1810 and 1820 and again between 1830 and 1840, seem consistent with narrative history. Exports had their initial impact in the first of those decades, whereas in the latter the effect of the Erie canal and the Ohio canal systems on interregional trade materialized more fully. Nevertheless, although these fluctuations capture some of the realities of the time, we do not wish to make too much of them because the methods of estimation have some bearing on the picture as well. For example, output is based largely on population 
growth, which was extremely rapid in the opening decades of the century (averaging nearly 15 percent per year). The agricultural labor force also grew very rapidly, but slightly slower, resulting in a productivity advance of 0.84 per year, which by assumption also materialized in the nonagricultural industries. Our methods are more appropriate for depicting longer-term changes, especially those between 1800 and 1840 or 1860 , and perhaps over 20 -year periods as well. ${ }^{16}$

Comparing sequential 20-year periods reveals that per capita output accelerated from 1.0 percent per year in the opening decades, to 1.2 percent in the middle period, to a noticeably more rapid 2.1 percent between 1840 and 1860 . The region's pattern of acceleration paralleled that for the nation, but was much sharper, especially if one compares the 20 years after 1840 with the 20 years before. Although the national figures do not support the idea of a take-off, the same cannot be said for the region. ${ }^{17}$

Our estimate of the region's performance between 1840 and 1860 contrasts noticeably with that of Robert Fogel and Stanley Engerman. According to them, the North Central region's per capita income was only 68 percent of the nation's in 1840 and rose slightly faster than the nation's between 1840 and $1860,1.6$ versus 1.4 percent per year. ${ }^{18}$ Our narrowly defined series reveals that the region's output per capita was 79 percent of the nation's in 1840 and grew noticeably faster between 1840 and $1860 .{ }^{19}$

\section{VARIATIONS IN CONSUMPTION PER CAPITA}

The preceding estimates, for both the region and the nation, were based on the assumption that per capita consumption of most farm products remained constant between 1800 and 1840. Gallman's work has indicated that this assumption is not an unreasonable one for the nation. He concluded that "whatever changes took place in per capita food consumption were probably limited to those arising out of shifts in the structure of the population." ${ }^{20}$ Although consumption may have changed more noticeably in some regions because shifts in the population structure were more pronounced, this does not appear to have occurred in the Old Northwest.

\footnotetext{
${ }^{16}$ The results for the 20-year periods seem more reliable because they are firmly anchored in the census evidence for 1820 and 1840 , and the direct estimates for 1840 and 1860 .

${ }^{17}$ The specter of a take-off is even more obvious in the broader measure in which the growth of output per capita accelerated from 0.74 to 1.8 percent per year.

${ }^{18}$ Fogel and Engerman, Time on the Cross, p. 248.

19 The difference in the rates of growth result from the estimates of noncommodity production. Fogel and Engerman relied on Easterlin's ("Regional Income Trends," p. 545) rough allocations of output to the region, whereas we made careful and detailed estimates for each major component of the nonagricultural sector. Our per capita figures are higher than theirs because we used national prices whereas they used regional ones.

${ }^{20}$ Gallman, "The Statistical Approach," pp. 76-78.
} 
We have estimated the effect of demographic changes on the region's consumption by following the methods that Gallman used for the nation. ${ }^{21}$ The shift in the makeup of the region's population between 1800 and 1840 , namely a decline in the share of children and a rise in the urban population, pushed up per capita consumption slightly. Given those changes, per capita production of basic agricultural output would have had to increase by only a little more than $\$ 1$, or by about 5 percent, in order for the dietary standards of each component of the population to have remained constant. As a result of that small difference, estimated GDP per capita would have grown slightly faster over the period, 1.19 percent per year instead of 1.11 percent $(0.58$ percent instead of 0.53 percent using the broad measure).

We have constructed a second set of estimates that allows for a positive income elasticity of demand for what we have called basic agricultural output. ${ }^{22}$ Engel's Law suggests that there should have been some increase in consumption in response to a rise in income. It is likely that Towne and Rasmussen implicitly took for granted that little growth in income had occurred before 1840 , so the assumption of no increase in consumption may have seemed reasonable to them. The conjectural estimates for the period 1800 to 1840 now make clear, however, that growth in income per capita did occur, so the assumption no longer seems as secure. While the income elasticity of demand for farm products may have been less than one, it seems unlikely that it was zero.

It may be that in a frontier region during an era of self-sufficiency, behavior consistent with Engel's Law did not manifest itself, or perhaps not as clearly and fully as theory would suggest. ${ }^{23}$ There are also other reasons why, at that time, a rise in income may not have caused the consumption of food to increase much. ${ }^{24}$ The demand for staple food items is likely to be more income-inelastic than food in general, and the distinction between finished food products purchased by consumers and the food output supplied by farms may be important. As incomes rose, consumers may have increased their consumption of additional services and characteristics embodied in the food, while the per capita supply (and consumption) of the basic product remained constant. The supply

\footnotetext{
${ }^{21}$ According to Gallman ("The Statistical Approach," pp. 71-77), the value of a typical slave diet was about one-third that of a typical free diet, that for children under 15 was one-half that of an adult, and that for urban dwellers was 50 percent greater than that of rural residents. Using these figures to weight the population in the Old Northwest at each benchmark date yields an index series on what we have called standardized consumption per capita. That series was then used to extrapolate the 1840 value of per capita consumption of basic agricultural output.

${ }^{22}$ For an earlier attempt to incorporate a positive income elasticity into the conjectural estimating equation, see Lindstrom, "American Economic Growth," and "Macroeconomic Growth," pp. 686-89, and David's "Comments," pp. 306-9.

${ }^{23}$ Of course, by 1820 , Ohio and perhaps Indiana must have reached the point where such behavior would have manifested itself.

${ }^{24}$ These ideas come from Clark, Huberman, and Lindert, "The British Food Puzzle."
} 
of the basic food products is the more relevant for gauging changes in an area devoted predominantly to agriculture.

Although there may be reasons to think that Engel's Law was not operative or that its effect was not very strong in the Old Northwest before 1840, we have estimated an alternative set of figures to explore the effects of the underlying assumption about per capita consumption. A positive income elasticity means, of course, that the estimates of agricultural production are dependent on the estimates of GDP per capita. Because our conjectural estimates of the latter depend on the former (see equation 1a), we had to solve simultaneously for agricultural and total output per person.

The results depend on the exact value of elasticity assumed to prevail. In Table 2 we have reported the results using an elasticity of demand for BAO of 0.6, a value found for later years in the United States. ${ }^{25}$ Given this assumed value, per capita consumption of basic agricultural output in the Old Northwest would have risen from $\$ 20$ in 1800 to $\$ 31$ in 1840. The growth of farm output required to have met this demand implies that output per capita (narrowly defined) increased by 1.77 percent per year between 1800 and 1840 , and 1.88 percent per year from 1800 to 1860 , somewhat faster than the rates revealed in the basic estimates.

The rates of growth generated with an assumed elasticity of 0.6 probably mark out the upper bound of the region's performance. Growth that fast entails a level of perishable consumption per person in 1800 that falls on the edge of plausibility. ${ }^{26}$ Consumption as low as only $\$ 20$ per person could conceivably have occurred in any particular year, but seems too low to have prevailed for any length of time.$^{27}$ Faster rates of growth imply even lower, and more implausible, levels of consumption. Thus between 1800 and 1860 the region's per capita output must have advanced between 1.44 percent, as implied in the basic estimates which assumed a zero income elasticity of demand, and

\footnotetext{
${ }^{25}$ Williamson found expenditure elasticities for food among Massachusetts households in 1875 to have been around 0.6 to 0.7 , depending on whether household size was taken into account and on the exact form of the estimating equation. These values were close to, but below, those estimated for the 20th century. Williamson, "Consumer Behavior," pp. 116-19, tables 4-6. This is also the value that Clark, Huberman, and Lindert ("The British Food Puzzle") cite as typical.

${ }^{26}$ Gallman, "The Statistical Approach," p. 78, estimated that the value of perishables consumed was $\$ 45$ in 1840 and $\$ 42$ in earlier years, figures well above our estimate of BAO. Part of the disparity arises because the former is valued at consumer prices and the latter at prices received by farmers. The difference represents the costs of distribution. If we assume that the 1840 ratio of 1.33 prevailed in earlier years then our $\$ 20$ estimate for BAO per capita is equivalent to about $\$ 27$ of perishable consumption, which is still a bit low.

27 Food consumption in any year was made up of that produced on farms plus that obtained by fishing and hunting. The 1840 figures for crops and livestock produced on farms must have represented a very large portion of total consumption, even in the Old Northwest. The values we extrapolated back to 1800 represent that 1840 level of consumption and production and imply that the same proportions were being produced on farms. In fact, a much larger share of consumption must have come from hunting and fishing in 1800 , but our output series does not specify how or when the shift from off-farm supplements to on-farm production took place.
} 
TABLE 2

ALTERNATIVE ESTIMATES OF OUTPUT PER CAPITA IN THE OLD NORTHWEST AND THE UNITED STATES, 1800-1860

\begin{tabular}{|c|c|c|c|c|}
\hline & \multicolumn{2}{|c|}{ Narrow Definition of Output } & \multicolumn{2}{|c|}{ Broad Definition of Output } \\
\hline & $\begin{array}{c}\text { Old } \\
\text { Northwest (\$) }\end{array}$ & $\begin{array}{c}\text { United } \\
\text { States (\$) }\end{array}$ & $\begin{array}{c}\text { Old } \\
\text { Northwest (\$) }\end{array}$ & $\begin{array}{c}\text { United } \\
\text { States (\$) }\end{array}$ \\
\hline 1800 & 36 & 57 & 60 & 68 \\
\hline 1810 & 41 & 61 & 63 & 73 \\
\hline 1820 & 51 & 64 & 69 & 75 \\
\hline 1830 & 56 & 74 & 71 & 85 \\
\hline 1840 & 73 & 91 & 87 & 101 \\
\hline 1850 & 83 & 100 & 98 & 111 \\
\hline 1860 & 111 & 124 & 124 & 134 \\
\hline \multicolumn{5}{|c|}{ Average Annualized Rates of Change } \\
\hline $1800-1810$ & 1.13 & 0.73 & 0.52 & 0.67 \\
\hline $1810-1820$ & 2.41 & 0.34 & 0.92 & 0.27 \\
\hline $1820-1830$ & 0.93 & 1.57 & 0.35 & 1.30 \\
\hline $1830-1840$ & 2.64 & 2.01 & 2.00 & 1.72 \\
\hline $1800-1820$ & 1.77 & 0.53 & 0.72 & 0.47 \\
\hline $1820-1840$ & 1.78 & 1.79 & 1.17 & 1.51 \\
\hline $1840-1860$ & 2.10 & 1.57 & 1.80 & 1.42 \\
\hline $1800-1840$ & 1.77 & 1.16 & 0.95 & 0.99 \\
\hline $1800-1860$ & 1.88 & 1.30 & 1.23 & 1.13 \\
\hline
\end{tabular}

Notes: Output per capita was obtained by solving the following equation for basic agricultural output per capita:

$$
b_{t}=\frac{-\left(e_{t}-b_{t+1}+\frac{n e_{t+1}}{1-n}\right)+\sqrt{\left(e_{t}-b_{t+1}+\frac{n e_{t+1}}{1-n}\right)^{2}+\left(\frac{4 e_{t} b_{t+1}}{1-n}\right)}}{2}
$$

where $b$ is per capita consumption of basic agricultural output (BAO); $n$ is the assumed value of the income elasticity of demand for BAO (in this case we assumed a value of 0.6 ); and $e$ is the production per capita of all other products, including the agricultural surplus. As the equation indicates, we take the known values for a given year $t+1$ and solve for output per capita in the previous year $t$. To simplify the calculation we assume that the value of all other production in each year is that derived in the basic estimates reported in Table 1. Per capita output is obtained by adding the estimated values of BAO per capita to the values of all other production.

Sources: Authors' calculations as explained in the text and von Ende and Weiss, "Appendix."

1.88 percent per year. Because the same consumption levels are implicit in the broad measure, our two sets of estimates for that series set the range between 0.95 and 1.23 percent per year. ${ }^{28}$

${ }^{28}$ The performance of the national economy would be altered as well by the relaxation of the assumption about the constancy of per capita consumption. If we assumed the same 0.6 income elasticity of demand for the nation, then its growth rate is raised by 0.2 percent per year between 1800 and 1860 , regardless of which output measure is used. It is possible, and perhaps likely, that the nation and region had different income elasticities of demand because they differed in their levels of economic development. 


\section{CONCLUSIONS}

The Old Northwest did very well economically in the early part of the nineteenth century. Under the assumption that per capita consumption of most farm products remained constant between 1800 and 1840 , its growth was equal to the nation's when output is measured broadly, and consistently outpaced the nation's when output is defined narrowly. If we allow for positive income elasticity of demand, the region's rates of growth reveal an even more notable achievement, although its performance relative to the nation's remains about the same. It appears that regardless of which assumption is used and whether output is measured narrowly or broadly, the Old Northwest, even in its earliest formative years, was one of the world's leading economic performers.

\section{REFERENCES}

Atack, Jeremy, and Fred Bateman, To Their Own Soil (Ames, IA, 1986).

Clark, Gregory, Michael Huberman, and Peter Lindert, "A British Food Puzzle, 1770-1850" (Mimeo, University of California, Davis, 1992).

Cohn, Raymond, "Antebellum Regional Incomes: Another Look," Explorations in Economic History, 18 (Oct. 1981), pp. 330-46.

David, Paul, "The Growth of Real Product in the United States Before 1840: New Evidence, Controlled Conjectures," this Journal, 27 (June 1967), pp. 151-97.

David, Paul, "Comment," this Journal, 39 (Mar. 1979), 303-9.

Easterlin, Richard, "Regional Income Trends, 1840-1950," in Seymour Harris, ed., American Economic History (New York, 1961), pp. 525-47.

Easterlin, Richard, "Farm Production and Income in Old and New Areas at MidCentury," in David Klingaman and Richard Vedder, eds., Essays in Nineteenth Century Economic History (Athens, OH, 1975), pp. 77-115.

Fogel, Robert and Engerman, Stanley, Time on the Cross (Boston, 1974).

Gallman, Robert, "Gross National Product in the United States, 1834-1909," Studies in Income and Wealth, 30 (1966), pp. 3-76.

Gallman, Robert, "The Statistical Approach: Fundamental Concepts Applied to History," in G. R. Taylor and L. F. Ellsworth, eds., Approaches to American Economic History (Charlottesville, VA, 1971), pp. 63-86.

Gallman, Robert, and Thomas Weiss, "The Service Industries in the Nineteenth Century," Studies in Income and Wealth, 34 (1969), pp. 287-381.

Hutchinson, William, "U.S. Regional Growth: The Proximate Causes, 1870-1910," (Mimeo, Miami University of Ohio, 1991).

Lindstrom, Diane, "American Economic Growth before 1840: New Evidence and New Directions," this Journal, 39 (Mar. 1979), pp. 289-301.

Lindstrom, Diane, "Macroeconomic Growth: The United States in the Nineteenth Century," Journal of Interdisciplinary History, 13 (Spring, 1983), pp. 679-705.

Meyer, David, "Midwestern Industrialization and the American Manufacturing Belt in the Nineteenth Century," this Journal, 49 (Dec. 1989), pp. 921-37.

Sokoloff, Kenneth, "Productivity Growth in Manufacturing During Early Industrialization," Studies in Income and Wealth, 51 (1986), pp. 679-736. 
Towne, Marvin, and Rasmussen, Wayne, "Farm Gross Product and Gross Investment in the Nineteenth Century," Studies in Income and Wealth, 24 (1960), pp. 255-312.

von Ende, Eleanor, "Conjectural Estimates of Economic Growth in the Old Northwest" (Ph.D. diss., University of Kansas, Lawrence, 1990).

von Ende, Eleanor, and Thomas Weiss, "Appendix to Consumption of Farm Output and Economic Growth in the Old Northwest, 1800 to 1860" (Mimeo, Texas Tech University, 1992).

Weiss, Thomas, "Estimates of Gross Domestic Product for the United States, 1800 to 1860" (Mimeo, University of Kansas, 1992).

Weiss, Thomas, "Economic Growth Before 1860: Revised Conjectures," in Donald Schaefer and Thomas Weiss, eds., American Economic Development in Historical Perspective (Palo Alto, CA, forthcoming).

Williamson, Jeffrey, "Consumer Behavior in the Nineteenth Century: Carroll D. Wright's Massachusetts Workers in 1875," Explorations in Entrepreneurial History, 4 (Winter 1967), pp. 98-135. 